\title{
Multispectral analysis of the Martian dayglow from UVIS-NOMAD on board TGO
}

EGU 21-5164 - Gérard et al.

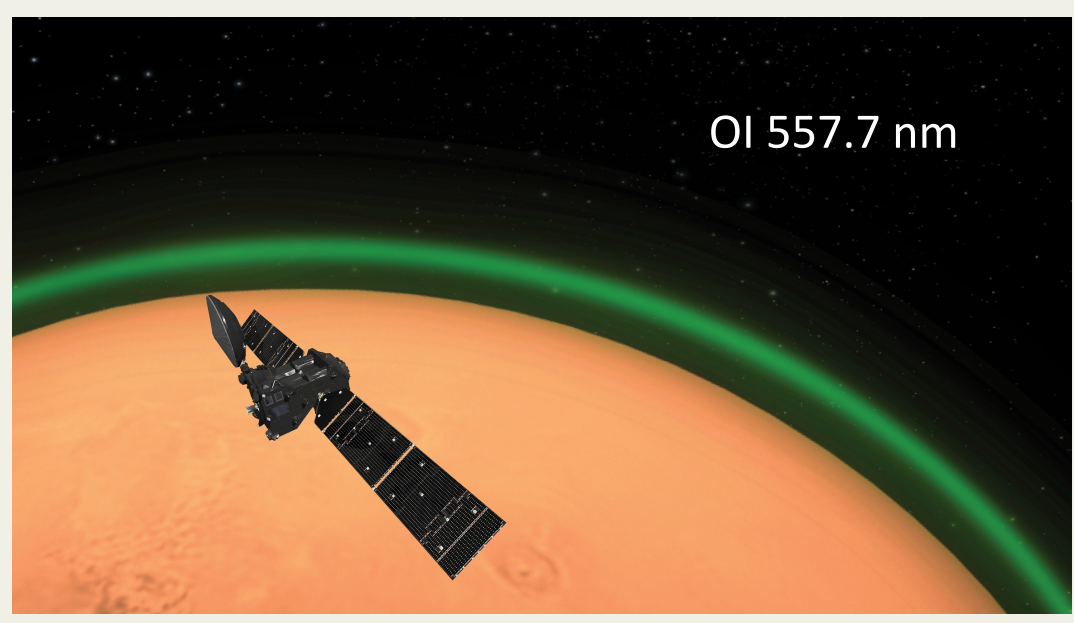

artist view

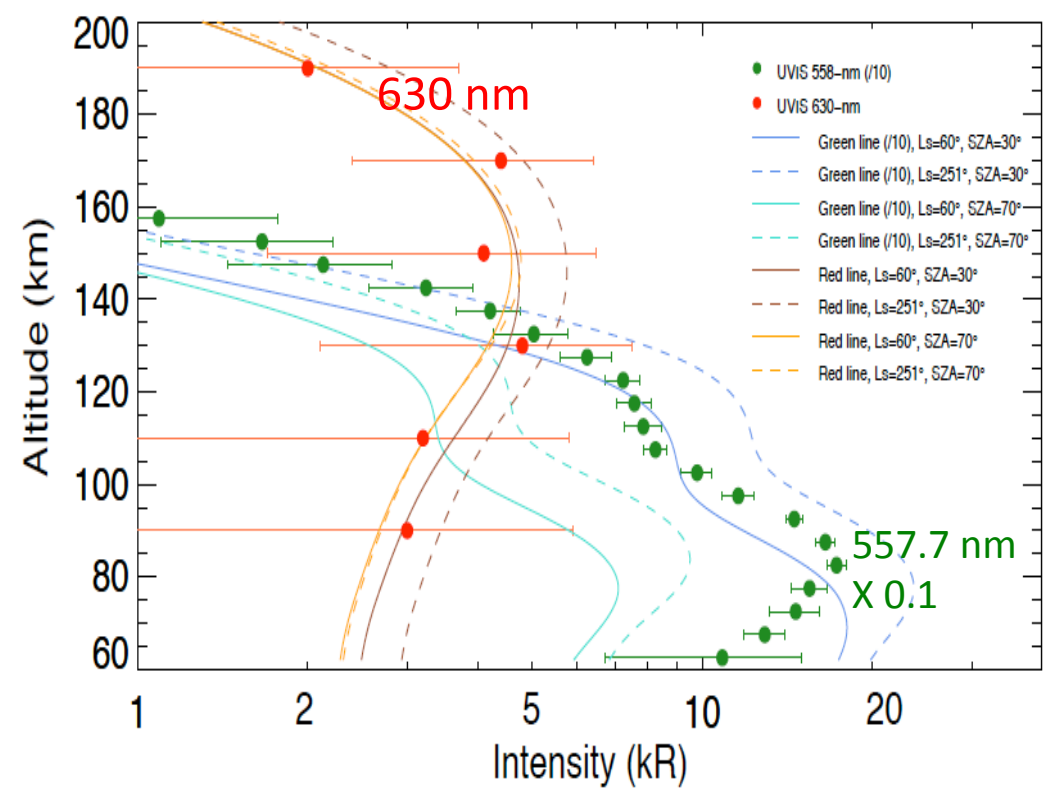

Both [OI] emissions have been detected in the Martian dayglow (dots). Model simulations for different conditions match the observed limb profiles (solid and dashed lines).

The UV-Visible UVIS spectrometer on board TGO has detected the presence of the oxygen 557.7 and $630 \mathrm{~nm}$ dayglow emissions (see fig.). Their distribution reflects the changes in the thermosphere throughout the Martian year. $\mathrm{CO}$ Cameron and $\mathrm{CO}_{2}^{+} \mathrm{MUV}$ and visible bands have also been observed. A new limb observing mode and key results will be described. 